\title{
Development of a profile scoring system for assessing the psychosocial situation of patients with chronic musculoskeletal pain
}

This article was published in the following Dove Press journal: Journal of Pain Research

I August 2017

Number of times this article has been viewed

\author{
Takuya Nikaido' \\ Shingo Fukuma ${ }^{2,3}$ \\ Takafumi Wakita ${ }^{4}$ \\ Miho Sekiguchi' \\ Shoji Yabuki' \\ Yoshihiro Onishi ${ }^{5}$ \\ Shunichi Fukuhara ${ }^{2,3}$ \\ Shin-ichi Konno'
}

On behalf of the profile scoring system for multilateral assessment of social factors in patients with chronic musculoskeletal pain study group

'Department of Orthopaedic Surgery, Fukushima Medical University School of Medicine, Fukushima, ${ }^{2}$ Department of Healthcare Epidemiology, Kyoto University, Graduate School of Medicine and Public Health, Kyoto, ${ }^{3}$ Center for Innovative Research for Communities and Clinical Excellence (CIRC2 ${ }^{2}$ E), Fukushima Medical

University, Fukushima, ${ }^{4}$ Department of Sociology, Kansai University, Osaka, Institute for Health Outcomes and Process Evaluation Research (iHope International), Kyoto, Japan
Correspondence: Takuya Nikaido Department of Orthopaedic Surgery, Fukushima Medical University School of Medicine, I Hikarigaoka, Fukushima City, Fukushima 9601295, Japan

Tel +8I 24547 I276

Fax +8I 245485505

Email tnikaido@fmu.ac.jp
Abstract: Chronic pain is a manifestation of interactions among physical, psychological, and social conditions, but the latter two, that is, the nonphysical correlates of chronic pain, are only rarely measured. This study aimed to develop a profile scoring system for assessing the psychosocial situation of patients with chronic musculoskeletal pain. An expert panel chose social and psychological domains considered to be relevant to patients with chronic pain and wrote questions asking about each of those domains. The questionnaire was completed by 252 patients with chronic musculoskeletal pain. Factor analysis was used to select questionnaire items for each domain. Associations and interactions of pain severity and each domain score with painrelated quality of life (PRQOL) were examined using linear regression models. Five domains were chosen: work, family, sleep, mental health, and PRQOL. Then, a total of 17 questions were created for the work, family, and sleep domains. Using the likelihood-ratio test, we found significant interactions with PRQOL in four pairs: severity-family, severity-mental, familysleep, and work-mental. The association between pain severity and PRQOL was related to each patient's social and psychological situation. These results suggest that interventions for patients with chronic pain may be personalized to account for each individual's psychosocial situation. Keywords: chronic musculoskeletal pain, psychosocial factors, family and work environment, pain-related quality of life, profile scoring system

\section{Introduction}

Chronic pain is a manifestation of interactions among physical, psychological, and social conditions. It results in a wide range of symptom burden and pain-related effects on quality of life (QOL). The National Health Interview Survey conducted in USA in 2012 revealed that over $11 \%$ of the adult population suffered from chronic pain. ${ }^{1}$ Health care resources were being wasted by ineffective treatments and doctor shopping for chronic pain, and many people were unable to work due to debilitating pain. Chronic pain is thus among the most important concerns for medicine and public health. Furthermore, a study conducted in 2011 found that as much as USD 600 billion is spent annually on various costs related to chronic pain (including treatment, work absences, and compensation). ${ }^{2}$ A similar problem exists in Japan as well, where an epidemiological study showed that about $15 \%$ of the population suffers from chronic pain. ${ }^{3}$ The Comprehensive Survey of Living Conditions in Japan, which is a nationally representative survey conducted by the Japanese government, reported that diseases associated with a high frequency of outpatient visits include low back pain, shoulder stiffness, joint pain, and headaches. In addition to the obvious burden on the 
individuals with pain, the large number of people in Japan who have some type of chronic musculoskeletal pain is an important burden on the society. ${ }^{4}$

Generally speaking, chronic pain (including chronic musculoskeletal pain) has become a major issue for the health care system. As chronic pain develops, the problem is no longer limited to organic abnormalities in the affected sites or physical functioning, and becomes both exacerbated and prolonged by complex interactions among physical factors, psychiatric factors, psychological factors, and sociological factors. In 2010, the Ministry of Health, Labor, and Welfare of Japan stated as follows:

\footnotetext{
"It is desirable to build a healthcare system that can provide comprehensive care surpassing the boundaries of clinical departments, and it is necessary for doctors and other medical professionals in various fields to collaborate in providing treatment". 5
}

In other countries as well, studies are focusing on the need for comprehensive assessment of chronic pain. ${ }^{2,6-8}$

It is not surprising for the severity of pain to be related to pain-related QOL, but the impact of pain on QOL can also depend on psychological and social factors; so, these factors should be considered in the care of patients with chronic pain. ${ }^{9}$ In this study, we developed a profile scoring system to assess the social and psychological situation of patients with chronic musculoskeletal pain. We then examined the association of psychosocial profile of the patient with their pain-related QOL, considering the likely interactions.

\section{Methods}

This study consisted of two steps. First, we convened an expert panel, and the panel members created a conceptual framework of domains that they judged to be relevant to the psychosocial situation of patients with chronic pain. Then, with those domains in mind, the panel members developed questions to ask patients. Second, we asked those questions in a survey of patients with chronic musculoskeletal pain.

The protocol for this study was approved by the Fukushima Medical University ethics committee, the Institutional Review Board of Gunma University Graduate School of Medicine, the ethics committee at the Shiga University of Medical Science, the research ethics committees of Graduate School of Medicine, Chiba University, the clinical study ethics committees of Sapporo Medical University Hospital, the ethical committee for clinical research of Hiroshima University, and the ethics committee of Graduate School of Medicine and Faculty of Medicine, the University of Tokyo.

\section{Development of domains and items for profile score}

The expert panel comprised 10 orthopedic surgeons, five anesthesiologists, and one psychiatrist. They identified five domains as being relevant to the psychosocial situation of patients with chronic pain: work (stress, interpersonal relations, and satisfaction); family (support); sleep (falling asleep, wakefulness, and use of sleep aids); mental health (depression and anxiety); and pain-related QOL (effects of pain on daily life and social life). For the mental health and pain-related QOL domains, subscales already developed for the Medical Outcomes Short Form-36 (SF-36) were used. ${ }^{10}$ These comprised the five items on the SF-36's Mental Health (MH) subscale and two items on the SF-36's Bodily Pain (BP) subscale. For the work, family, and sleep domains, three new pools of items were created by the expert panel. (These new pools had nine items, four items, and four items, respectively; see below for details). Possible responses to the new items were "yes" and "no".

\section{Participants in the survey}

The participants were outpatients at orthopedic clinics and pain clinics associated with 13 research institutes around Japan during the period from February 2012 to October 2013. The inclusion criteria were: 1 ) diagnosis by an orthopedic surgeon of a spinal disease, joint disorder, or complex regional pain syndrome and 2) pain with a rating of at least 1 on a numeric rating scale (NRS; an 11-point scale from 0 to 10) that had persisted for at least the last 3 months. Sample size was determined as 250 because we needed enough power to conduct exploratory linear regression model including 20-25 potential predictors. ${ }^{11}$

\section{Measurement}

After the participants provided written informed consent, they were given a self-administered anonymous questionnaire at the outpatient office, and they returned the questionnaire before they left the clinic. In addition to the questions mentioned above, one question about the severity of the pain (by NRS) and one question about the duration of the pain were included. Information on each participant's demographics and clinical information was obtained from the medical records.

\section{Item selection and scoring}

For the newly developed work, family, and sleep items, factor analysis (principal factor method) was used for each domain, separately. Factor loadings were used to select items. We planned to select three items for each of work, family, and 
sleep domains, so that the total number of items included in the profile scoring system would not be too large. Raw scores for each domain were standardized to obtain a mean score of 50 and a standard deviation (SD) of 10. Because each domain score is calculated by a few selected items, we had a plan to use domain score as the ordinal variable in the following analyses. Norm-based scoring with a mean of 50 and an SD of 10 was used to compute scores on the SF-36 $\mathrm{MH}$ and BP subscales. All scores were adjusted to be lower for participants with more severe problems.

\section{Reliability of each domain score}

Reliability of domain scores was tested for the family, sleep, and mental health (SF-36 MH) domains using Cronbach's $\alpha$. Larger values of Cronbach's $\alpha$ indicate higher reliability, and values $\geq 0.7$ are generally considered to indicate acceptable reliability. ${ }^{12}$ Reliability tests were not performed with the work domain or with the SF-36 BP because each had only two items and it is usually difficult to estimate the values of Cronbach's $\alpha$.

\section{Association between severity of pain and pain-related QOL}

To examine the association between patient characteristics and pain severity, we assigned each participant to one of three groups. The groups were defined by tertiles of NRS of pain severity (low $0-5$, middle 6-7, and high 8-10). We then summarized the characteristics of the patients in each category.

To estimate the strength of the association between the severity of pain and pain-related QOL (SF-36 BP), we used a linear regression model that included severity of pain, family domain score, sleep domain score, mental health score, diagnosis, and duration of pain. We examined the interactions of domain scores with pain-related QOL using the likelihood-ratio (LR) test. $P$-values $<0.05$ for the LR test indicate statistically significant interaction between a domain score and the severity of pain. In addition, in analyzing data from the participants who were employed, we included the work domain score in the model and examined the association and interaction of that score with pain-related QOL. To examine the association between severity of pain and painrelated QOL, we conducted multivariate linear regression model including the interaction terms of severity-family (reference category of family domain score was set to the low category) and severity-mental (reference value of mental health score was set to 50).

The data were analyzed with STATA 14.1 (Stata Corporation, College Station, TX, USA) and SPSS 22.0 (IBM Corporation, Chicago, IL, USA).

\section{Results}

\section{Patient characteristics by severity of pain}

Between February 2012 and October 2013, we consecutively selected outpatients with chronic musculoskeletal pain at orthopedic or associated pain clinics. A total of 252 patients were registered during the study period. The characteristics of participants by their severity of pain are shown in Table 1 . Their mean age was 64.1 years, and over $60 \%$ were women. The most common disease was spinal disease, followed by joint disorder, and then complex regional pain syndrome. At the time of the survey, more than two-thirds of the participants (67.1\%) had had chronic pain for $>2$ years. Participants in the lowest pain severity category were generally younger

Table I Characteristics by severity of pain

\begin{tabular}{|c|c|c|c|c|}
\hline \multirow[t]{2}{*}{$\overline{\text { Characteristic }}$} & \multirow[t]{2}{*}{ All, $N=252$} & \multicolumn{3}{|c|}{ Severity of pain } \\
\hline & & Low, $n=92$ & Middle, $n=70$ & High, $n=64$ \\
\hline Age, mean (SD), years & $64.1(16.1)$ & $62.0(18.1)$ & $65.0(14.2)$ & $63.3(15.1)$ \\
\hline Female/male & $96 / 154$ & $35 / 57$ & $27 / 43$ & $23 / 40$ \\
\hline \multicolumn{5}{|l|}{ Diagnosis } \\
\hline Spinal disease ${ }^{\mathrm{a}}$ & $|3|(52.0 \%)$ & 45 (48.9\%) & 35 (50.0\%) & 37 (57.8\%) \\
\hline Joint disorder ${ }^{b}$ & $73(29.0 \%)$ & 28 (30.4\%) & $21(30.0 \%)$ & $15(23.4 \%)$ \\
\hline CRPS & $32(12.7 \%)$ & $10(10.9 \%)$ & II (I5.7\%) & $9(14.1 \%)$ \\
\hline Other, unknownc & 16 (6.4\%) & $9(9.8 \%)$ & $3(4.3 \%)$ & $3(4.7 \%)$ \\
\hline \multicolumn{5}{|l|}{ Duration of pain } \\
\hline$<6$ months & 14 (5.6\%) & $4(4.4 \%)$ & $4(5.7 \%)$ & $4(6.5 \%)$ \\
\hline 6 months-I year & $23(9.2 \%)$ & II (12.1\%) & $5(7.1 \%)$ & $5(8.1 \%)$ \\
\hline $\mathrm{I}-2$ years & $45(18.1 \%)$ & $22(24.2 \%)$ & $7(10.0 \%)$ & $10(16.1 \%)$ \\
\hline$>2$ years & $167(67.1 \%)$ & $54(59.3 \%)$ & $54(77.1 \%)$ & 43 (69.4\%) \\
\hline
\end{tabular}

Notes: aLumbar spinal stenosis, $n=66$; lumbar spondylosis, $n=30$; herniated lumbar disk, $n=21$; multiple diseases, $n=4$. ' $O$ steoarthritis of the knee, $n=49$; degenerative hip disease, $n=25$. ${ }^{c}$ Comorbid spinal disease and joint disorder, $n=7$; unknown, $n=8$.

Abbreviation: CRPS, complex regional pain syndrome. 
than those in the other two categories. The participants in the three pain severity groups did not differ with regard to diagnosis or duration of pain.

\section{Item selection}

The questions regarding work, family, and sleep that were newly developed in this study are shown in Table 2, along with each question's factor loading within its domain and the final selections for the profile. Of the nine questions in the work domain, the three with the highest factor loadings were selected. Of the four questions in the family domain, the latter two asked about facts rather than patients' perceptions and were not associated with the former two, and so, they were not included in the profile. The four questions in the sleep domain were highly correlated, but the last question was removed because it had the lowest factor loading and it asked about a behavior rather than patients' perceptions.

Cronbach's $\alpha$ values for family, sleep, and SF-36 MH from the selected questions were 0.792, 0.729, and 0.850, respectively, indicating acceptable reliability. As noted above, Cronbach's $\alpha$ was not calculated for the SF-36 BP and work domains because they contained only two ques-

Table 2 Results of factor analysis of items in the three newly developed domains

\begin{tabular}{|c|c|}
\hline Item & $\begin{array}{l}\text { Factor } \\
\text { loading }\end{array}$ \\
\hline \multicolumn{2}{|l|}{ Work } \\
\hline Are you satisfied with your work environment? & 0.804 \\
\hline Are you satisfied with your work? & 0.774 \\
\hline $\begin{array}{l}\text { Are you satisfied with your interpersonal } \\
\text { relations at work? }\end{array}$ & 0.707 \\
\hline Do you enjoy your job? & 0.655 \\
\hline Do you get along well with your boss(es)? & 0.642 \\
\hline Are you satisfied with your income? & 0.369 \\
\hline $\begin{array}{l}\text { Can you yourself decide the order or procedure of } \\
\text { your work? }\end{array}$ & 0.272 \\
\hline $\begin{array}{l}\text { Do you have someone to consult with regarding } \\
\text { difficulties at work? }\end{array}$ & -0.263 \\
\hline Have you ever taken a day off of work because of pain? & -0.017 \\
\hline \multicolumn{2}{|l|}{ Family } \\
\hline Do family problems cause you stress? & 0.704 \\
\hline Do you enjoy spending time with your family? & -0.304 \\
\hline Does anyone in your family require nursing care? & 0.192 \\
\hline $\begin{array}{l}\text { Does anyone else in your family suffer from the same } \\
\text { type of pain that you have? }\end{array}$ & -0.016 \\
\hline \multicolumn{2}{|l|}{ Sleep } \\
\hline Do you often have difficulty falling asleep? & 0.755 \\
\hline $\begin{array}{l}\text { Do you often wake up early and have difficulty } \\
\text { falling back asleep? }\end{array}$ & 0.677 \\
\hline Do you often wake up in the middle of the night? & 0.634 \\
\hline Do you use sleep aids? & 0.541 \\
\hline
\end{tabular}

Note: Items chosen for the profile are in bold. tions. Table 3 shows the coefficients of correlation between the three domains of family, work, and sleep. The correlation coefficients were low, indicating that the three domains were independent of each other.

\section{Association between pain severity and pain-related QOL}

Table 4 shows the association between severity of pain and pain-related QOL. In the unadjusted model, each one-point increase in the severity of pain was associated with a 1.8point decrease in pain-related QOL. Even after adjusting for domain scores (family, sleep, mental health), type of diagnosis, and duration of pain, we found statistically significant associations between severity of pain and pain-related QOL $(-1.71,95 \%$ CI: -2.16 to -1.26$)$. Although we did not find a statistically significant association between pain-related

Table 3 The correlation coefficients of correlation between domains

\begin{tabular}{|c|c|c|c|c|c|}
\hline & Family & Work & Sleep & $\begin{array}{l}\text { Mental } \\
\text { health }\end{array}$ & $\begin{array}{l}\text { Body } \\
\text { pain }\end{array}$ \\
\hline Family & & 0.075 & 0.133 & 0.167 & 0.012 \\
\hline Work & & & -0.039 & 0.220 & 0.143 \\
\hline Sleep & & & & $0.37 I$ & 0.199 \\
\hline Mental health & & & & & 0.523 \\
\hline Body pain & & & & & \\
\hline
\end{tabular}

Table 4 Association between severity of pain and pain-related $\mathrm{QOL}$

\begin{tabular}{|c|c|c|}
\hline Variables & & $\begin{array}{l}\text { Mean difference in } \\
\text { pain-related } \\
\text { QOL }(95 \% \mathrm{Cl})\end{array}$ \\
\hline \multicolumn{3}{|l|}{ Crude analysis } \\
\hline Severity of pain & Each one-point increase & $-1.80(-2.19$ to -1.41$)$ \\
\hline \multicolumn{3}{|l|}{ Multivariable analysis } \\
\hline Severity of pain & Each one-point increase & $-1.71(-2.16$ to -1.26$)$ \\
\hline \multirow[t]{3}{*}{ Family } & Low & Reference \\
\hline & Middle & $-1.65(-5.70$ to 2.40$)$ \\
\hline & High & $-1.96(-5.98$ to 2.07$)$ \\
\hline \multirow[t]{4}{*}{ Sleep } & Low & Reference \\
\hline & Low-Middle & $-1.49(-4.59$ to 1.61$)$ \\
\hline & High-Middle & $-0.52(-3.48$ to 2.44$)$ \\
\hline & High & $-1.29(-3.98$ to 1.40$)$ \\
\hline Mental health & Each one-point increase & $0.16(0.06-0.27)$ \\
\hline \multirow[t]{4}{*}{ Diagnosis } & Spinal disease & Reference \\
\hline & Joint disorder & $0.92(-1.26$ to 3.11$)$ \\
\hline & CRPS & $-0.73(-3.95$ to 2.48$)$ \\
\hline & Other, unknown & $2.89(-1.00$ to 6.77$)$ \\
\hline \multirow[t]{4}{*}{ Duration of pain } & $<6$ months & Reference \\
\hline & 6 months-I year & $3.07(-2.73$ to 8.88$)$ \\
\hline & $\mathrm{I}-2$ years & $3.54(-1.67$ to 8.74$)$ \\
\hline & $>2$ years & $2.86(-1.99$ to 7.72$)$ \\
\hline
\end{tabular}

Abbreviations: CRPS, complex regional pain syndrome; QOL, quality of life. 
QOL and the scores in the family and sleep domains, there was a statistically significant interaction between the severity of pain and the family domain score $(P$-value for interaction by LR test $=0.01)$ and also the mental health score $(P$-value for interaction by LR test $<0.01$ ).

In the model including the domain score of work for the subgroup of workers, we did not find a statistically significant association between the work score and pain-related QOL (Table 5). Although we did not find a statistically significant interaction between the work domain score and the severity of pain on pain-related QOL $(P$-value for interaction by LR test $=0.24$ ), we did find a statistically significant interaction between the work domain score and the mental health score on pain-related QOL ( $P$-value for interaction by LR test $=0.02$ ).

Interactions between the domain scores on pain-related QOL are summarized in Table 6. We found significant interactions in four pairs: severity-family, severity-mental, family-sleep, and work-mental. We found that each onepoint increase in the severity of pain was associated with a 3.4-point decrease ( $95 \% \mathrm{CI}:-5.25$ to -1.61$)$ in pain-related QOL after taking into account those interactions.

\section{Discussion}

In this study, we developed the chronic pain profile tool to assess the psychosocial conditions of patients with chronic pain and to examine how these conditions relate to the association between pain severity and pain-related QOL. Use of this profiling system may help physicians to personalize patient care.

\section{Importance of a chronic pain profile}

Social and psychological conditions have been assessed in the management of chronic pain. ${ }^{13-16}$ However, patients' social situations, which are diverse and vary greatly among individuals, have received less objective evaluation. In fact, almost no reports have described tools for systematically

Table 5 Association between work and pain-related QOL

\begin{tabular}{lll}
\hline Variable & & $\begin{array}{l}\text { Mean difference in } \\
\text { pain-related QOL } \\
(\mathbf{9 5 \%} \mathbf{~ C l})\end{array}$ \\
\hline Work & Low & Reference \\
& Low to middle & $-2.05(-8.06$ to 3.97$)$ \\
& High to middle & $1.42(-4.87$ to 7.71$)$ \\
& High & $-0.34(-5.15$ to 4.48$)$ \\
\hline
\end{tabular}

Note: Model including severity of pain, family domain score, sleep domain score, SF-36 MH score, diagnosis, and duration of pain, in addition to work domain score. Abbreviations: QOL, quality of life; SF-36 MH, Short Form-36 Mental Health subscale. assessing the social situation of people with chronic pain. In this context, the chronic pain profile that we developed in this study could promote a more systematic and standardized assessment of the social and psychological situation of people with chronic pain, because it relies on patients' responses to specific questions rather than on outsiders' unsystematic and indirect impressions. This profile could help clinicians to identify issues in a patient's social life that are particularly salient to that individual. To the extent that it is sensitive to problems regarding work, family, sleep, pain-related QOL, and mental health, it could be useful in deciding on targets for therapeutic interventions.

\section{Development process}

The profile development process in this study has several strengths. First, the domains and the questions within each domain were chosen by an expert panel consisting mainly of researchers who have investigated chronic pain and the psychosocial situations of patients with orthopedic conditions. Second, the participants in this study comprised a diverse group of patients from multiple facilities of various sizes throughout Japan. This should help increase the generalizability of the profiling system. Third, factor analysis was used to select questionnaire items and a standard psychometric procedure was used to confirm the reliability of scores in each domain. The resulting profiling system comprising only 15 items enables evaluation of psychosocial issues involving family, work, sleep, mental health, and pain-related QOL. The questionnaire can conveniently be used even in outpatient clinics.

\section{Association of pain severity and pain- related $\mathrm{QOL}$}

Pain severity was associated with pain-related QOL even after adjustments were made for the type of diagnosis, duration of pain, and domain scores of family and sleep (Table 3 ). In the care of patients with chronic pain, it is natural for clinicians to emphasize symptom severity and diagnoses, but we should also put a high value on assessing a variety of other aspects of each patient's background. We found significant interactions with pain-related QOL between the domain scores. The association between the severity of pain and pain-related QOL was modified by the participants' social and psychological situations (Table 5). For example, the association between pain severity and pain-related QOL was related to the family score and the mental health score. Patients with family problems are more likely to have lower QOL than patients without these problems, even if both groups suffer from pain 
Table 6 -values for interactions with pain-related quality of life (likelihood-ratio test)

\begin{tabular}{lllll}
\hline & Severity of pain & Family & Work & Sleep \\
\hline Severity of pain & - & & & \\
Family & $\mathbf{0 . 0 1}$ & - & & \\
Work & $0.24^{*}$ & $0.28^{*}$ & - & \\
Sleep & 0.57 & $<\mathbf{0 . 0 1}$ & $0.39 *$ & - \\
Mental health & $<\mathbf{0 . 0 1}$ & 0.20 & $\mathbf{0 . 0 2 *}$ & 0.13 \\
\hline
\end{tabular}

Note: *Models including the work score were examined only in the subgroup of workers $(n=60)$. Data in bold indicates statistical significance.

of similar severity. These results indicate that health professionals should focus their attention on the problems of family, sleep, work, and mental health when they take care of patients with chronic pain. Because it gives clinicians information about each patient's social and psychological situation, this profile scoring system may be helpful in personalizing the care of patients with chronic pain.

\section{Limitations}

Some limitations need to be considered when interpreting the study results. First, only one group of participants was investigated. It is, therefore, possible that the results were optimized for that specific group, and the profile needs to be tested with other groups. Second, the initial pools of questions for the family domain and the sleep domain each comprised only four items. This leaves room for increasing measurement accuracy, and possibly also increasing measurement precision, by using a larger item pool at the start. Furthermore, only "yes" and "no" options were used for questions in the work, family, and sleep domains. As a result, score variation would be small and may have been insensitive to individual differences. As an improvement, a Likert scale or other multioption scale could be used for the responses. Third, we measured the work domain score only in the subgroup of workers. Therefore, $P$-values for interactions in the model including the work score should be interpreted with caution. These models may not have had enough power to detect interactions due to the small sample size. Fourth, no pain-specific specialists or psychologists were included in the expert panel. Because we aimed to develop a profile scoring system focusing on chronic musculoskeletal pain, we mainly included experts of musculoskeletal pain from orthopedic surgeons. We also included five anesthesiologists and one psychiatrist who usually treat patients with chronic pain.

\section{Conclusion}

Almost no reports have described the tools for systematically assessing the psychosocial situations of patients with chronic musculoskeletal pain, even though it is well accepted that social and psychological conditions can affect these patients' QOL. ${ }^{16}$ The profile scoring system developed in this study focuses on the social and psychological conditions. Use of this profiling system may help clinicians to personalize patient care.

\section{Acknowledgment}

Members of the profile scoring system for psychosocial situation of chronic musculoskeletal pain study group are listed here. Chairman: Shin-ichi Konno (Department of Orthopaedic Surgery, Fukushima Medical University School of Medicine). Research members: Shin-ichi Konno, Shoji Yabuki, Miho Sekiguchi, Takuya Nikaido (Department of Orthopaedic Surgery, Fukushima Medical University School of Medicine); Jiro Kurata (Department of Anesthesiology, Tokyo Medical and Dental University School of Medicine); Yoshitetsu Oshiro (Himeji Ishikawa Functional Brain Imaging Laboratory); Shigeru Saito (Department of Anesthesiology, Gunma University Graduate School of Medicine); Sei Fukui (Pain Management Clinic, Department of Anesthesiology, Shiga University of Medical Science Hospital); Seiji Ohtori (Department of Orthopaedic Surgery, Graduate School of Medicine, Chiba University); Makoto Nishihara (Department of Integrative Physiology, National Institute for Physiological Sciences); Tsuneo Takebayashi (Department of Orthopaedic Surgery, Sapporo Medical University School of Medicine); Mamoru Kawakami (Department of Orthopaedic Surgery, Wakayama Medical University Kihoku Hospital, Wakayama); Mitsuo Ochi (Department of Orthopaedic Surgery, Graduate School of Biomedical and Health Sciences, Hiroshima University); Katsushi Takeshita (Department of Orthopaedic Surgery, Faculty of Medicine, the University of Tokyo); Morio Matsumoto (Department of Orthopaedic Surgery, Keio University School of Medicine); Masahiko Sumitani (Department of Anesthesiology and Pain Relief Center, the University of Tokyo). Research associate members: Hiroshi Kawaguchi (Department of Orthopaedic Surgery, Faculty of Medicine, the University of Tokyo); Nobuo Adachi, Takeshi Hiramatsu (Department of Orthopaedic Surgery, Graduate School of Biomedical and Health Sciences, Hiroshima University); Yuichi Ogino (Department of Anesthesiology, Gunma University Graduate School of Medicine). This manuscript was supported by the Health Labour and Science Research Grant for research on chronic pain.

\section{Author contributions}

All authors made substantial contributions to conception and design, acquisition of data, or analysis and interpretation of 
data; took part in drafting the article or revising it critically for important intellectual content; gave final approval of the version to be published; and agree to be accountable for all aspects of the work. Panel members of the research groups listed in Acknowledgments section contributed to developing the risk profile system.

\section{Disclosure}

The authors report no conflicts of interest in this work.

\section{References}

1. Nahin RL. Estimates of pain prevalence and severity in adults: United States, 2012. J Pain. 2015;16(8):769-780.

2. Institute of Medicine (US) Committee on Advancing Pain Research, Care, and Education. Relieving pain in America: a blueprint for transforming prevention, care, education, and research. Washington, DC: National Academies Press (US); 2011.

3. Nakamura M, Nishiwaki Y, Ushida T, Toyama Y. Prevalence and characteristics of chronic musculoskeletal pain in Japan. J Orthop Sci. 2011;16(4):424-432.

4. Ministry of Health, Labour and Welfare. Summary Report of Comprehensive Survey of Living Conditions 2010. Tokyo: Ministry of Health, Labour and Welfare; 2010. Available from: http://www.mhlw.go.jp/english/ database/db-hss/dl/report_gaikyo_2010.pdf. Accessed: June 25, 2017.

5. Proposal for management of chronic pain. Minist. Health Labour Welf. Jpn. Available from: www.mhlw.go.jp/stf/houdou/2r9852000000ro8fatt/2r9852000000roas.pdf. Accessed January 25, 2017.
6. Gatchel RJ. A biopsychosocial overview of pretreatment screening of patients with pain. Clin J Pain. 2001;17(3):192-199.

7. Turk DC, Audette J, Levy RM, Mackey SC, Stanos S. Assessment and treatment of psychosocial comorbidities in patients with neuropathic pain. Mayo Clin Proc. 2010;85(3 Suppl):S42-S50.

8. Williams DA. The importance of psychological assessment in chronic pain. Curr Opin Urol. 2013;23(6):554-559.

9. Takahashi N, Kikuchi S, Konno S, et al. Discrepancy between disability and the severity of low back pain: demographic, psychologic, and employment-related factors. Spine (Phila Pa 1976). 2006;31(8):931-939; discussion 940 .

10. Ware JE, Sherbourne CD. The MOS 36-item short-form health survey (SF36). I. Conceptual framework and item selection. Med Care. 1992;30(6): 473-483.

11. Austin PC, Steyerberg EW. The number of subjects per variable required in linear regression analyses. J Clin Epidemiol. 2015;68(6): 627-636.

12. Nunnally JC, Bernstein IH. Psychometric Theory. 3rd ed. New York, NY: McGraw-Hill; 1994.

13. Bair MJ, Robinson RL, Katon W, Kroenke K. Depression and pain comorbidity: a literature review. Arch Intern Med. 2003;163(20): 2433-2445.

14. Leeuw M, Goossens ME, Linton SJ, Crombez G, Boersma K, Vlaeyen JW. The fear-avoidance model of musculoskeletal pain: current state of scientific evidence. J Behav Med. 2007;30(1):77-94.

15. Mallen CD, Peat G, Thomas E, Dunn KM, Croft PR. Prognostic factors for musculoskeletal pain in primary care: a systematic review. $\mathrm{Br} \mathrm{JGen}$ Pract. 2007;57(541):655-661.

16. Rucker KS, Metzler HM, Kregel J. Standardization of chronic pain assessment: a multiperspective approach. Clin J Pain. 1996;12(2): 94-110.
Journal of Pain Research

\section{Publish your work in this journal}

The Journal of Pain Research is an international, peer reviewed, open access, online journal that welcomes laboratory and clinical findings in the fields of pain research and the prevention and management of pain. Original research, reviews, symposium reports, hypothesis formation and commentaries are all considered for publication.

\section{Dovepress}

The manuscript management system is completely online and includes a very quick and fair peer-review system, which is all easy to use. Visit http://www.dovepress.com/testimonials.php to read real quotes from published authors. 